\title{
Synthesis of non-edible biodiesel from crude jatropha oil and used cooking oil
}

\author{
Syazwana Sapee ${ }^{1}$, Ahmad Fitri Yusop ${ }^{1,2,}$, Mohammad Nazri Mohd Jaafar ${ }^{3}$, Rizalman \\ Mamat $^{1}$, Wan Asma Ibrahim ${ }^{4}$, Hazir Farouk ${ }^{5}$, Norwazan Abdul Rahim ${ }^{6}$, Ilyia Syafira Ab \\ Razak $^{3}$, Muhammad Syahiran Abdul Malik ${ }^{3}$ and Zhang Bo ${ }^{7}$ \\ ${ }^{1}$ Faculty of Mechanical Engineering, Universiti Malaysia Pahang, 26600 Pekan, Pahang, Malaysia \\ ${ }^{2}$ Automotive Engineering Centre, Universiti Malaysia Pahang, 26600 Pekan, Pahang, Malaysia \\ ${ }^{3}$ Institute for Vehicle System and Engineering (IVeSE), Faculty of Mechanical Engineering, \\ Universiti Teknologi Malaysia, 81310 Skudai, Johor, Malaysia \\ ${ }^{4}$ Forest Research Institute Malaysia (FRIM), Kepong, 52109 Selangor, Malaysia \\ ${ }^{5}$ Department of Mechanical Engineering, Faculty of Engineering, Sudan University of Science and \\ Technology (SUST), 11111 Khartoum, Sudan \\ ${ }^{6}$ Department of Mechanical Engineering, Faculty of Engineering, Universiti Pertahanan Nasional \\ Malaysia, Kem Sg. Besi, 57000 Kuala Lumpur, Malaysia \\ ${ }^{7}$ School of Mechanical Engineering, Ningxia University, 750021 P. R. China
}

\begin{abstract}
This study focuses on a feasibility study of alternative nonedible crude oil such as jatropha and used cooking oil in biodiesel production. Crude jatropha oil (CJO) and used cooking oil (UCO) were converted to biodiesel using a two-step transesterification process with presents of acid-based and alkaline-based catalysts. Each three biodiesel blends (B5, B15 and B25) have been produced by blended with conventional diesel fuel (CDF). Determination of the fuel properties for each blend including CDF, Jatropha Methyl Ester (JME) and Used Cooking Oil Methyl Ester (UCOME) have been carried out. The average yield for jatropha and used cooking oil biodiesels production was $94.3 \%$ and $92 \%$ respectively. The increment of the percentage of JME or UCOME in its blends is proportional to fuels physical properties such as density, specific gravity, kinematic viscosity and surface tension, however inversely proportional to fuels calorific value. Based on the results of this study, it is acceptable to conclude that non-edible CJO and UCO are viable alternatives to edible oil as feedstock to renewable fuel in order to reduce the greenhouse gases produced.
\end{abstract}

\section{Introduction}

Fossil fuel has been the main source for energising almost all sectors including industrial, transportation and agricultural sectors. However, the resources are wiping out each day. Issues of global warming, fuel reserves shortage and raises of fuel prices, have driven scholars since decades ago to eagerly look up for the new solution of alternative fuels that

\footnotetext{
*Corresponding author: fitriy@ump.edu.my
} 
are available, technically feasible, economically viable and environmentally acceptable [13].

One of the choices of alternative fuels is biodiesel. It is also known as fatty acid methyl ester (FAME), is an alternative to fuel that is renewable, biodegradable, non-toxic, and possess lower aromatic content which can be obtained from feedstock $[4,5]$. Biodiesel is a group of ester-based oxygenated fuel produced from fatty acid triglycerides contained in animal fats, vegetable oils or waste vegetable oil, for instance, used cooking oil [6]. It is sustainable and due to the lighter carbon and sulphur contents compared to fossil fuel, they are environmentally friendly [7]. Biodiesel purest form is named B100, and it can be blended with petroleum or diesel at a different percentage, denoted as biodiesel blend [8]. It possesses higher density, viscosity and surface tension compared to conventional diesel fuel, that normally is used directly in an engine without modifications [9]. Usually, biodiesel feedstock is obtained from vegetable oils, for instance palm, sunflower, canola, and soy. But the production of biodiesel from edible feedstocks will somehow affect the food crops for the constantly growing population. Thus, the continuing and never-ending 'food versus fuel' debate throughout the world organisations.

Jatropha (Jatropha curcas L.) is a vegetable that contains non-edible oils [10]. The plantation of jatropha has many advantages as its ability to cultivate on dry land can increase the fertility on that particular land [11]. Its seed production is reported could produce around $0.8 \mathrm{~kg}$ seed per square meter per year [12]. The yield or conversion rate of CJO from its seed is said to be about $30 \%$ to $40 \%$ by weight whereas its kernel could produce CJO around $45 \%$ to $60 \%$ [13].

Another potential substitute to edible-vegetable-oil for biodiesel production is used cooking oil (UCO). UCO is categorised as non-edible feedstock plus has a lower price than pure feedstock such as palm oil, coconut oil and corn oil since it is a used product [14]. About 193,000 tons per year nationwide UCO is discarded into the dustbin, onto soil and into drainage system [15]. Besides recycling and reusing the UCO to reduce the wastage pollution, UCO also can be used as biodiesel due to its biodiesel production cost is competitive to petroleum diesel price. The production of biodiesel from UCO proves to be a right solution, efficiently and economically to utilise it.

Hence, the feasibility study particularly their conversion rate on these two types of biodiesel production is necessary. This study practices the two-step transesterification process to convert CJO and UCO to Jatropha Methyl Ester (JME) and Used Cooking Oil Methyl Ester (UCOME) respectively. JME (also known as jatropha biodiesel) and UCOME (named as UCO biodiesel) are produced by using alcohol and catalyst in transesterification process to convert triglycerides into fatty acid alkyl ester [16]. This research will be in depth on the approaches of producing these biodiesel using acid and alkaline catalysts, as well as focusing on the physical properties of the biodiesels to meet the biodiesel standard including its production cost $[4,6,17,18]$.

\section{Material and Methods}

\subsection{Feedstocks}

Crude oils used as feedstock for this research were obtained from few resources. CJO were procured from Bionass Sdn Bhd, Kuala Lumpur, Malaysia. UCO was supplied from Forest Research Institute Malaysia (FRIM), Kuala Lumpur, Malaysia. CDF was purchased from PETRONAS petrol station in Johor Bahru, Malaysia. 


\subsection{Synthesis of biodiesel procedures}

A two-step transesterification process was chosen to produce biodiesel in this study. The process started with pre-treatment of crude oil, and then acid catalysed esterification to produce esterified oil, followed by base catalysed transesterification, and finally posttreatment of unpurified methyl ester to obtain clear methyl ester/ biodiesel. Table 1 shown summary of a two-step transesterification process. Synthesis of biodiesel was conducted inhouse at Gas Turbine Combustion Research Group laboratory, Universiti Teknologi Malaysia, Johor, Malaysia.

Table 1. Summary of a two-step transesterification process

\begin{tabular}{|c|c|l|l|}
\hline Step & \multicolumn{1}{|c|}{ Process } & \multicolumn{1}{c|}{ Purpose } & \multicolumn{1}{c|}{ Product } \\
\hline 1 & Pre-treatment & To remove moisture & Refined oil \\
\hline 2 & Esterification & $\begin{array}{l}\text { To reduce the acid value of the crude } \\
\text { oil }\end{array}$ & Esterified oil \\
\hline 3 & Transesterification & To produce the methyl ester & Unpurified methyl ester \\
\hline 4 & Post-treatment & To purify the produced methyl ester & Clear methyl ester \\
\hline
\end{tabular}

Pre-treatment process is an initial process to convert crude oil to biodiesel. Crude oils sometimes are exposed to surrounding and react with air, adding moist to the fuel. Thus, the purpose of this process is to remove the moisture contained in crude oil. The crude oil was heated using a magnetic hot plate in a beaker at $90-95^{\circ} \mathrm{C}$ for 1 hour under vacuum.

Esterification process is an additional step of biodiesel production to reduce the value of free fatty acid in the crude oil to $1 \%$ or below by weight using an acid catalyst. This study used methanol $(\mathrm{MeOH})$ with alcohol to oil ratio is $12: 1$ molar ratio of $50 \%$ volume to volume. Sulphuric acid $\left(\mathrm{H}_{2} \mathrm{SO}_{4}\right)$ is added with a catalyst to oil ratio is $1.5 \%$ volume to volume to enhance reaction condition and conversion rate of biodiesel. The reaction was started and maintained at $65^{\circ} \mathrm{C}$ for 3 hours at $400 \mathrm{rpm}$.

Transesterification process is one of the main methods that have been used due to low cost and easy to perform. In this process, triglycerides (the main component of natural fats and oil) reacts with alcohol in presence of a catalyst, produces methyl ester and by-product glycerin. This study used $\mathrm{MeOH}$, with alcohol to oil ratio is 6:1 molar ratio of $25 \%$ volume to volume. Potassium Hydroxide $(\mathrm{KOH})$ as a base catalyst is added with $\mathrm{KOH}$ to oil ratio is $1 \%$ volume to volume. Transesterification reaction was maintained at $60^{\circ} \mathrm{C}$ for 2 hours at $400 \mathrm{rpm}$.

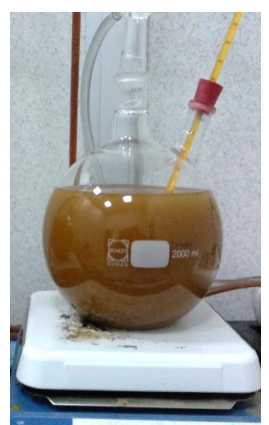

(a)

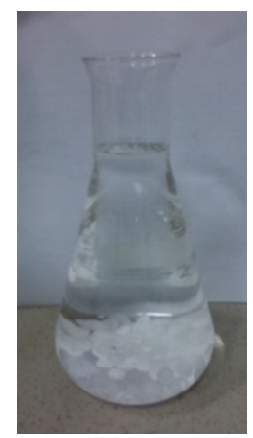

(b)

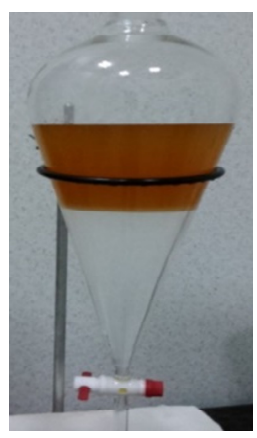

(c)

Figure 1. (a) Esterification reaction, (b) $\mathrm{KOH}$ dissolved in $\mathrm{MeOH}$, methoxide preparation for the transesterification process, (c) Post-treatment process of washing unpurified jatropha methyl ester.

Post-treatment process of two-step transesterification process is the final process to obtain methyl ester or biodiesel. The main purpose of this process is to purify the produced 
methyl ester from the transesterification process. The unpurified methyl ester is washed using $50 \%$ volume to volume distilled water at $50^{\circ} \mathrm{C}-60^{\circ} \mathrm{C}$ repeatedly to remove excess alcohol, catalyst and residual glycerol. The methyl ester then needs to be dried at $70^{\circ} \mathrm{C}$ for about 30 minutes at $400 \mathrm{rpm}$ to drive out any remaining methanol and moisture.

\subsection{Blending test fuels}

This research focuses on low proportion blends as test fuels, as it is significant in terms of economic and application in industries. In order to get a low percentage of blends, the blending process must be carried out between pure biodiesel and conventional diesel fuel (CDF) by volume. In this study, B5, B15 and B25 were chosen for both jatropha methyl ester (JME) and used cooking oil methyl ester (UCOME) blends. Blending process was conducted using simple manual blend techniques.

\subsection{Determining fuel physicochemical properties}

All of the physicochemical properties tests were conducted in-house at Universiti Teknologi Malaysia by considering many international standard procedures and testing. Properties of the test fuels determined were density, specific gravity, kinematic viscosity, surface tension at room temperature, as well as calorific value. Table 2 shows measuring devices that were utilised in this study, which comply with ASTM (American Society for Testing and Materials) standard specification.

Table 2. Measuring standards and devices for fuel properties determination

\begin{tabular}{|c|c|c|}
\hline Properties & Standard & Measuring Device \\
\hline Density $\left(\mathrm{g} / \mathrm{cm}^{3}\right)$ & ASTM D941 & A\&D N92 balance and Pycnometer \\
\hline Specific Gravity & ASTM D891 & Hydrometer \\
\hline $\begin{array}{c}\text { Kinematic Viscosity @ } 40^{\circ} \mathrm{C} \\
\left(\mathrm{mm}^{2} / \mathrm{s}\right)\end{array}$ & ASTM D445 & $\begin{array}{c}\text { Anton Paar stabinger viscometer } \\
\text { SVM3000 }\end{array}$ \\
\hline Surface Tension $(\mathrm{mN} / \mathrm{m})$ & ASTM D971 & Kruss K20Tensiometer \\
\hline Calorific Value $(\mathrm{kJ} / \mathrm{kg})$ & ASTM D240 & IKA C2000Bomb Calorimeter \\
\hline
\end{tabular}

\section{Result and discussions}

\subsection{Synthesis of biodiesel}

Figure 2 shows a sample of JME and UCOME produced. Both methyl esters were produced by conversion from crude oil via a two-step transesterification process. In term of physical appearances, both biodiesels have darker colour compared to diesel fuel due to their crude oils' colour. Yield or conversion rate is a ratio of quantity end product produced to amount provided at first. From the production, the average yield percentage of JME is 94.3\% whereas UCOME is $92.0 \%$. The conversion rate of biodiesel production is depending on parameters such as the ratio of methanol to crude oil, the ratio of catalyst, reaction temperature and time. Human error factor during handling the product also considered as one of the contributions to total conversion rate. 


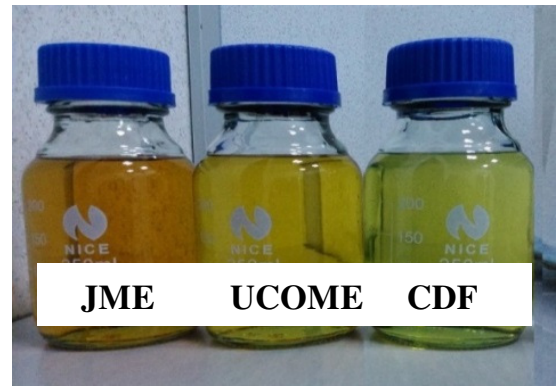

Figure 2. Samples of JME, UCOME and CDF

\subsection{Fuel physicochemical properties}

The fuel physical properties acquired are compared to the diesel standard (EN 590) and biodiesel standard (EN 14214). Table 3 shows the summary of the test fuels physical properties. Calorific value is defined as the energy content in a fuel and thus their efficiency [19]. From the table, it is observed that biodiesels have lower calorific value, which indicated that they contain lower energy as compared to diesel. A fuel with very high viscosity will destruct the fuel injector then vaporise poorly, resulting in high quantity of carbon build up [20]. Despite high viscosity, both B100 biodiesels produced complied to biodiesel standard EN14214. Surface tension is the molecules force of attraction, affecting fuel atomization in combustion [21]. Biodiesel's surface tension is higher than diesel. As surface tension increases, fuel atomization is degrading. Besides surface tension and viscosity, density and specific gravity of biodiesel blends is increase with the increases of biodiesel content in diesel fuel.

Table 3. Fuel Physiochemical Properties

\begin{tabular}{|c|c|c|c|c|c|}
\hline $\begin{array}{l}\text { Physical } \\
\text { Properties }\end{array}$ & $\begin{array}{c}\begin{array}{c}\text { Density } \\
\left(\mathbf{k g} / \mathbf{m}^{\mathbf{3}}\right)\end{array} \\
\text { ASTM } \\
\text { D941 }\end{array}$ & $\begin{array}{c}\text { Specific } \\
\text { Gravity } \\
\text { ASTM } \\
\text { D891 }\end{array}$ & $\begin{array}{c}\begin{array}{c}\text { Kinematic } \\
\text { Viscosity } \\
\left(\mathbf{m m}^{2} / \mathbf{s}\right)\end{array} \\
\text { ASTM D445 }\end{array}$ & $\begin{array}{c}\text { Surface } \\
\text { Tension } \\
(\mathbf{m N} / \mathbf{m}) \\
\text { ASTM } \\
\text { D971 }\end{array}$ & 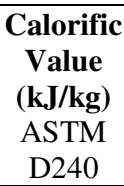 \\
\hline EN 590 & $820-845$ & - & $2.0-4.5$ & - & - \\
\hline Diesel (CDF) & 830.1 & 0.835 & 3.5020 & 29.5 & 45.29 \\
\hline B5 JME & 833.8 & 0.839 & 3.5802 & 29.7 & 44.83 \\
\hline B15 JME & 837.4 & 0.840 & 3.6795 & 29.9 & 44.21 \\
\hline B25 JME & 841.0 & 0.843 & 3.7110 & 30.1 & 43.59 \\
\hline B100 JME & 868.0 & 0.865 & 4.4761 & 31.6 & 39.52 \\
\hline B5 UCOME & 827.4 & 0.836 & 3.5833 & 29.7 & 44.93 \\
\hline B15 UCOME & 830.5 & 0.837 & 3.6520 & 29.9 & 44.35 \\
\hline B25 UCOME & 833.5 & 0.840 & 3.7511 & 30.0 & 43.73 \\
\hline B100 UCOME & 858.7 & 0.853 & 4.5184 & 32.1 & 39.50 \\
\hline EN 14214 & $860-900$ & - & $3.5-5.0$ & - & - \\
\hline
\end{tabular}

\section{Conclusions}

Biodiesel could be produced from two-step transesterification process. The conversion rate for biodiesels production is $94.3 \%$ for JME and $92.0 \%$ of yield percentage for UCOME. As the increment of the percentage of biodiesel in its blends, the physical properties of fuel such as density, specific gravity, kinematic viscosity and surface tension are also increasing. On the other hand, it is not applied to the calorific value. 
The percentage of biodiesel in its blends are inversely proportional to test fuels calorific value. All in all, JME blends and UCOME blends show a promising future in solving not only our food problem but also waste and pollution problems regardless of lower effectiveness compared to the current conventional fuel.

The authors would like to thank Ministry of Higher Education (MOHE), Universiti Teknologi Malaysia, Forest Research Institute Malaysia, and Universiti Malaysia Pahang for their funding under RDU Grants, RDU 1703144, RDU 172204, RDU 1603126 and RDU 1703314.

\section{References}

1. S.A. Basha, K.R. Gopal, S. Jebaraj, Renewable and Sustainable Energy Reviews, 13, 1628 (2009)

2. A. Demirbas, Energy Convers. Manage., 50, 14 (2009)

3. T.P. Durrett, C. Benning, J. Ohlrogge, The Plant Journal, 54, 593 (2008)

4. H.K. Ng, S. Gan, Appl. Therm. Eng., 30, 2476 (2010)

5. P.-M. Yang, K.C. Lin, Y.-C. Lin, S.-R. Jhang, S.-C. Chen, Appl. Therm. Eng., 100, 628 (2016)

6. N. Abdul Rahim, M.N. Mohd Jaafar, S. Sapee, H.F. Elraheem, Energies, 9, 659 (2016)

7. S. Senthilkumar, G. Sivakumar, S. Manoharan, Alexandria Engineering Journal, 54, 423 (2015)

8. A. Srivastava, R. Prasad, Renewable and sustainable energy reviews, 4, 111 (2000)

9. C.-Y. Lin, H.-A. Lin, Fuel Process. Technol., 89, 1237 (2008)

10. L. Yingying, L. Houfang, W. Jiang, L.I. Dongsheng, L.I.U. Shijie, B. Liang, Chin. J. Chem. Eng., 20, 740 (2012)

11. M.S. Kumar, A. Ramesh, B. Nagalingam, Biomass Bioenergy, 25, 309 (2003)

12. N. Foidl, G. Foidl, M. Sanchez, M. Mittelbach, S. Hackel, Bioresour. Technol., 58, 77 (1996)

13. P.K. Sahoo, L.M. Das, Fuel, 88, 994 (2009)

14. M. Canakci, J. Van Gerpen. A pilot plant to produce biodiesel from high free fatty acid feedstocks. American Society of Agricultural and Biological Engineers.

15. H. Ka, K. Sa, T. Aya, Health and Environ J, 4, 76 (2013)

16. H.E. Hoydonckx, D.E. De Vos, S.A. Chavan, P.A. Jacobs, Top. Catal., 27, 83 (2004)

17. H. Farouk, M. Nazri, A.E. Atabani, J. Teknologi (Sci. Engin.), 69, 65 (2014)

18. A. Rehman, D.R. Phalke, R. Pandey, Renewable energy, 36, 2635 (2011)

19. R. Verduzco, I. Botiz, D.L. Pickel, S.M. Kilbey, K. Hong, E. Dimasi, S.B. Darling, Macromolecules, 44, 530 (2011)

20. P. Campus, European Journal of Scientific Research, 58, 238 (2011)

21. B. Esteban, J.-R. Riba, G. Baquero, R. Puig, A. Rius, Fuel, 102, 231 (2012) 